Journal of Social Sciences 6 (1): 8-13, 2010

ISSN 1549-3652

(C) 2010 Science Publications

\title{
Family Values and Female's Psychological Aggression
}

\author{
Ali Edalati, Ma'rof Redzuan, Mariani Mansor and Mansor Abu Talib \\ Department of Family Ecology, Faculty of Human Ecology, University Putra Malaysia, Malaysia
}

\begin{abstract}
Problem statement: The main objective of the current study is to determine the relationship between women's perceptions toward Iranian family values with psychological aggression. Approach: All of the randomly selected 337 wives who suffered from level of psychological aggression were included in this study. Straus questionnaire (CTS) is the method used to measure psychological aggression. It shows a negative relationship between family values (inequality in affairs and inequality in regulation) and psychological aggression. It has also shown that there is no relationship between values of inequality in access job and inequality in political in relation to psychological aggression. Social learning theory is used in order to gain a thorough understanding of the issue. The multivariate regression analysis is utilized to answer the last objective. Results: The analysis showed that among the four predictor variables, two of which variables such as inequality in affairs and inequality in regulation were found to be significant in explaining the observed variation in psychological aggression (DV). Conclusion: Generally, the final model has explained $4 \%$ of total observed variance in psychological aggression.
\end{abstract}

Key words: Women aggression, family values, female aggression, psychological aggression

\section{INTRODUCTION}

The Iranian society is experiencing changes from a traditional society to a modern status. As a result, the Iranian families, especially the women of these families, are always been traditionally facing more problems compared to other family members. In other words, modern society values and the current views put the woman in bad conditions. Women are not expected by the society to become uncontrollable, angry and hard as far as they are considered to be the symbol of kindness, peace and benevolence. Accordingly, this unexpected change of behaviour among women may be the result of the neglect and ignorance of their rights from early birth onwards. Thus, it is worth to investigate scholastically these differences which will affect the family in particular and the society in general. Social learning theory clearly recognizes the fact that people can learn behaviour without directly experiencing it and in absence of any rewards (new values and norms). However, rewards are very important in motivating people to later perform the behaviour. In the current research, the equality of situation in the family are also been considered.

On the other hand, the roles played by factorsgender-bias and variables-across families are almost obvious worldwide. In Iran, the structure of family changes and is under the processes of structuring and restructuring continuously. Therefore, any attitude towards family should benefit from the new generation's attitude toward the concept of family as well as the society values. This ensures a permanent and sustainable development of value-system with respect to individuals' rights regardless of their gender. It sounds wise to assume that a man who lives in a patriarchal society will not apprehend to this problem. For instance, according to the Iranian constitution and religion (consist of both rules of civic law and rules of Shariat), a wife cannot leave the house without her husband's permission. The insurance for a woman's death in an accident is half of a man's based on the stated policy.

After the divorce, children's protection is always given to the man. More importantly, the man has the right to divorce his wife. The laws and rules do not give such rights to the women. Women's testimony in the court is not equal to men in terms of the numbers. That is, two women are needed to testify in the court if in case they are going to be considered as witnesses. The girl cannot marry without her father's permission (Kar, 2000a). Based on the current practice, it is therefore an absolute need to analyze women's problems from different points of view such as family values, economical, social, political and judicial perspectives.

Corresponding Author: Ali Edalati, Department of Family Ecology, Faculty of Human Ecology, University Putra Malaysia, Malaysia Tel: 0060122793206 
Aggression might be an effect of contradictory views regarding the values between the old generations and the younger ones. Therefore, this research focuses on the Iranian family values and their effects on wife's aggression which are considered to be the major variables in this controversy.

The primary concern of the issue is to observe the changes of attitudes and values across generations in the Iranian society. About two decades ago that women possessed some independence and are able to benefit from social and economic advantages. In conclusion, it must be mentioned that there is no doubt in respect to the movement and evolution of ideas and the expansion of values. In other words, the process of globalization and industrialization will continue to increase in future. It must be confessed that, it is practically impossible to prevent the penetration of information through modern and expanding technology. Moreover, the influence of Western ideas in all aspects of life by the Iranian younger generations became a constant source of stress in the family. This further reinforces the existing male and female conflicts, as young generation of women will be exposed to the gender egalitarian values of western culture (Kar, 2000b). The rate of observed female aggression across the Iranian families will be directly affected by these influential variables.

Previous research: A number of studies have been focused on the psychological aspect of aggression. For instance, sample comprising of 453 couples, who were cohabiting and had a child, were questioned with the use of the CTS2 and a scale to assess their participants for aggression by their partners. Meanwhile, O'Leary and Slep (2006) discovered that women were more likely to commit both mild aggressions, with around $23.8 \%$ as compared to 33.8 and $8.4 \%$ (compared to Vs $11.5 \%)$ for severe aggression. This study indicated that men were more likely to claim partner physical aggression once reporting their experience of physical aggression as compared to women. Physical aggression of women was probably a response partner's psychological aggression. Therefore, it was concluded that women escalated aggression which are caused by their attempt to defend violently.

Psychological aggression is a technique that wives use in their fights. It is more common than physical aggression (Shook et al., 2002). Dutton (2006), in his research and treatment in the area of couple violence, he offers much insight, particularly to therapists and policy makers with regard to family conflicts. He further concluded that men are likely as women to be victims and both suffer similar physical and psychological outcomes of spousal conflict. Harned
(2001) argued that females are more likely to perpetrate psychological aggression than males. Ehzazi (2004) found respondents to report psychological abuse more than physical abuse.

About 1,635 couples were requested to complete the CTS in the study by Caetano et al. (2002). The study yields to $40 \%$ of the agreement in relation to mutual partner violence. In addition, across the three ethnic groups, wives were reported to commit more partner violence compared to their spouses. This finding has evidently provided support to the race-free and ethnicity-free profile of violence. Nevertheless, the findings gathered were observed to be in conformity with other available studies. In relation to other studies, the same distribution which carried more or less similarities has been observed. Using the CTS in their experimental study on 120 students (61 males and 59 females), Simonelli et al. (2002) found that both genders (i.e., $10 \%$ of males and $33 \%$ of females) had committed at least one type of physical aggressive behaviours. In addition, $18 \%$ of males and $15 \%$ of females were also found to have been under physical aggression from their partners.

Objectives: The general objective of this study is to determine the relationships between perception of women toward Iranian traditional values and psychological aggression among married women in Shiraz city, Iran. However, the clustered variables are subdivided into the following specific objectives:

- To describe the perception of women toward Iranian family values and psychological aggression among respondents

- To examine the relationships between Iranian family values (inequality in getting job, regular, family affairs and politic) and female psychological aggression among respondents

- To determine the factor which uniquely predicts psychological aggression

\section{MATERIALS AND METHODS}

The current study was conducted in Shiraz city, Iran which provided the researcher with an adequate sample of aggressive women. Moreover, there are over sixty clinics for guidance and family counseling in this city. Having a population of around 1,800,000 people, Shiraz is the fourth biggest city and the biggest southern city in Iran. The population of the study included 3510 aggressive married women in Shiraz who were referred for counselling. Compared with divorced and incomplete families, these families better 
represent the interaction among family members especially the one between spouses which plays a significant role in aggression in the families. In addition, these women outnumbered the others so the findings of the study on them can be generalized to many other similar cases. The sample size needed to derive with the research findings was determined using the formula suggested by Krejcie and Morgan (1970).

Out of the whole population, a final number of 346 women were selected. Nine cases were excluded due to incomplete questionnaires or information provided. From each clinic, the sample was chosen according to the proportional number of aggressive women that were referred to them. From clinic region one 53 (15.31\%), region two $55(15.89 \%)$, region three 55 (15.89\%), region four $58(16.76 \%)$, region five $60(17.34)$ and region six $65(18.78 \%)$ The above proportion of participating individuals was sustained across the research procedure.

Conflict Tactic Scale (CTS) was originally developed by Straus (1979). It measures physical and psychological aggression in couples that are dating, cohabiting or married. The questions used in this study include the subscales of psychological aggression. The translation of this instrument, its validity and reliability had already been established and provided to the participants. The Cronbach Alpha value for conflict tactic scale was 0.79 .

Iranian family Values scale is a combination of four indexes of inequality in family affairs, employment, regulation implementation and political issues. For the purpose of this study, only family affairs were taken into account which included 19 items. This scale combined of 49 items. There are 25 items with negative aspects and 24 items with positive features of gender inequality. It is a reliable test with the alpha being observed at 0.77 . Women's opinions related to the traditional values of Iran have been categorized under the five groups of strongly disagree, disagree, neutral, agree and strongly agree. To assess the perceptions of women toward Iranian family values, this scale was used.

The reliability test was employed to measure the reliability of the study instruments. The Cronbach alpha test was used for this purpose. A representative sample of 35 subjects answered the scales to help the researcher calculate and measure the internal consistency reliability. The results appear in the Table 1.

The data collected from personal interviews are exported to the computer and were analyzed utilizing the computer software of Statistical Package for Social Sciences (SPSS) version 16th. In order to facilitate the data analysis, the following statistical procedure was employed.
Table 1: Reliability coefficients Cronbach alpha

\begin{tabular}{lcc}
\hline Scale & CTS & FM \\
\hline $\begin{array}{l}\text { Current } \\
\text { Coefficients }\end{array}$ & 0.79 & 0.77 \\
Research & & \\
\hline
\end{tabular}

FM: Family values; CTS: Conflict Tactic Scale

Bivariate correlations were used to compare the relationships between two variables. There are also ordinal and interval variables for which the Likert type scale was used to measure 1 disagree strongly, 2 disagree, 3 unsure, 4 agree and 5 agree strongly.

Multiple regression analysis was used to determine the links between a range of independent variables and female aggression. This analysis results in the development of a formula that further explains variance in the dependent variable. In other words, this analysis helps to identify independent variables that can be combined to form the best prediction of the dependent variable.

\section{RESULTS}

The data of the participants is provided in (Table 2-4).

For "the mean for family affairs" it was observed to be $\mathrm{M}=50.23, \mathrm{SD}=7.04$. Approximately, 59 $(17.5 \%)$ of the respondents have agreed with traditional family values, while $253(75.1 \%)$ were located as mediocre and $25(7.4 \%)$ were found to disagree with the traditional values. It can be interpreted that majority of the respondents were either be unsupportive to the traditional values or were examining their position to adopt the new family values. For the values of inequality in politics, it was observed that $\mathrm{M}=14.53$, $\mathrm{SD}=4.74$; for values inequality in access to job $\mathrm{M}=$ $22.07, \mathrm{SD}=5.67$; for inequality in family affairs $\mathrm{M}=$ $50.23, \mathrm{SD}=7.03$, while for inequality in regulations $\mathrm{M}=36.83, \mathrm{SD}=8.45$. Generally, majority of the respondents were in the medium level of the four domains of perceptions of family values. However, when high level (agree) and the low level (not agree) of the perception towards family values are compared, more respondents were found to be in the high level from all four domains of perceptions. It reflects that more respondents perceived the occurrence of inequalities in family affairs, regulations, access to job and politics compared to those who disagreed. In Iranian culture, there are new values emerged in relations to family values.

The new values include the right to choose a spouse, decision making about family, having the right 
to ask for divorce, choosing their job based on their own will, men's cooperation in cooking and childcare and finally supervising the family, all of which are referred to in this study. The more women are becoming educated, the more chances they will be detached from the traditional values. The wide coverage of mass media and improvement in literacy and education level have encouraged the women to be more familiar with their own rights and to reject the traditions or values which are against their interests and count the women to enjoy inferior rights compared to men. This has finally helped women replace the values which regard to equal values for both men and women.

Table 2: Perception of women toward Iranian Traditional Values and level of Aggression

\begin{tabular}{|c|c|c|c|c|}
\hline Variables & $\mathrm{n}$ & Percent & Mean & SD \\
\hline Inequality in Family Affairs & & & 50.23 & 7.03 \\
\hline Agree $(<43)$ & 59 & 17.5 & & \\
\hline Medium (43-59) & 253 & 75.1 & & \\
\hline Not Agree (>59) & 25 & 7.4 & & \\
\hline Inequality in Regulations & & & 36.83 & 8.45 \\
\hline Agree $(<32)$ & 103 & 30.6 & & \\
\hline Medium (32-46) & 198 & 58.8 & & \\
\hline Not Agree $(>46)$ & 36 & 10.7 & & \\
\hline Inequality in Access to Job & & & 22.07 & 5.66 \\
\hline Agree $(<20)$ & 130 & 38.6 & & \\
\hline Medium (20-31) & 191 & 56.7 & & \\
\hline Not Agree (>31) & 16 & 4.7 & & \\
\hline Inequality in Politics & & & 14.53 & 4.74 \\
\hline Agree $(<14)$ & 179 & 53.1 & & \\
\hline Medium (14-22) & 140 & 41.5 & & \\
\hline Not Agree $(>22)$ & 18 & 5.3 & & \\
\hline Psychological aggression (337) & & & 19.28 & 8.13 \\
\hline Low $(<12)$ & 78 & 23.1 & & \\
\hline Medium (12-24) & 164 & 48.7 & & \\
\hline High $(>24)$ & 95 & 28.8 & & \\
\hline
\end{tabular}

Table 3: Correlation between perception toward traditional values and aggression

\begin{tabular}{lll}
\hline & Correlation coefficient $(\mathrm{r})$ & \\
& - & \\
Variables & Psychological aggression & Sig \\
\hline Inequality in affairs & $-0.153^{* *}$ & 0.000 \\
Inequality in regulation & $-0.146^{* *}$ & 0.000 \\
Inequality in access job & -0.005 & 0.929 \\
Inequality in political & 0.014 & 0.800 \\
\hline$* *: \mathrm{p}<0.01 ; * \mathrm{p}<0.05$ & &
\end{tabular}

Table 4: Summary of regression analysis of the main variables contributing to psychological aggression

\begin{tabular}{|c|c|c|c|c|c|}
\hline $\begin{array}{l}\text { Predictors } \\
\text { of DV }\end{array}$ & $\begin{array}{l}\text { Unstandardized } \\
\text { coefficients }\end{array}$ & Std. error & $\begin{array}{l}\text { Beta } \\
\text { unstandardized } \\
\text { coefficients }\end{array}$ & $\mathrm{t}$ & p-value \\
\hline Constant & 28.068 & 3.186 & & 8.810 & 0.000 \\
\hline Political & 0.090 & 0.114 & 0.053 & 0.790 & 0.430 \\
\hline Access job & 0.113 & 0.103 & 0.079 & 1.105 & 0.270 \\
\hline Regulation & -0.115 & 0.062 & -0.119 & -1.844 & 0.049 \\
\hline Affairs & -0.167 & 0.077 & -0.144 & -2.156 & 0.032 \\
\hline
\end{tabular}

For psychological aggression, mean was observed $\mathrm{m}=19.28$ and standard deviation was $\mathrm{SD}=8.13$. It could be realized that, approximately $(23.1 \% ; 78)$ of respondents have a low level of psychological aggression, whereas, $(48.7 \%$; 164) of them have medium psychological aggression and $(28.2 \%$; 95$)$ of respondents have high levels of psychological aggression (Table 2).

The Pearson's product-moment correlation test was utilized to determine the relationship between perception of women toward four types of Iranian traditional values (inequality in affairs, inequality in regulation, inequality in access job and inequality in political) and psychological aggression. There was a negative and significant relationship between perception of women toward Inequality in Affairs and psychological aggression where, $r=-0.153$ and $p<0.01$.

There was a negative and significant relationship between Inequality in Regulation and psychological aggression where, $r=-0.146$ and $p<0.01$. As it can be seen, inequality in regulation was negatively correlated with psychological aggression.

There was no significant relationship between Inequality in Access Job and psychological aggression where, $r=0.929$ and $p<0.05$. There was no significant relationship between Inequality in Political and psychological aggression where, $r=0.014$ and $p<0.05$ (Table 4).

Factors which contribute to the women's psychological aggression: The Multivariate Regression Analysis was used to answer the last objective. The analysis showed that among the 4 predictor variables, two of which variables such as inequality in regulation and inequality in family affairs, were found to be significant in explaining the observed variation in psychological aggression (DV). Generally, the final model has explained $4 \%$ of total observed variance in psychological aggression.

In the model, the first variable which is known as inequality in regulation, explained the highest variance to psychological aggression and its result is further supported by Pearson product moments correlation analysis. It follows that inequality in family affairs explained the next highest variance to psychological aggression (DV). The other variables such as inequality in politics and inequality in access job, did not explain any significant variance in psychological aggression (DV).

\section{DISCUSSION}

It was observed that as the disagreement with traditional values rules increases, the degree of 
aggression decreases. The reason might be that women are having more appropriate understanding of the present values of the society in which they are living. Consequently, they choose their partners more consciously. They usually have known their husbands before the marriage. Such women will most likely to face fewer problems and rarely show aggression with their husbands as compared to traditional women. As Moazami (2004) has identified in her study, one of the reasons for family crimes and murdering of spouses in families is economic dependence of women on their husbands. Despite the dissatisfaction with marital life, women continue to live with their husbands because they are worried about losing their children.

On the other hand, from the time the women will spend most of their time in reading newspapers and watching television, they will be exposed to inequalities aroused from the existing values in the family and society. When they face a problem in their relationship, they may consider this problem as related to the value and social structure of the family values. They may also look for the cause of this problem in their society structure and they do not attribute it to their husbands. In addition, due to the spread of satellite, international television and radio programs encouraging new and Western culture, such housewives are likely to ask for equality of rights and to have more responsibility in social and familial issues. As such, women are brought up in the new society and developed a negative attitude toward that and are almost sceptical toward traditional family values. So aggression is not an inherent but a learned behaviour and follows the learning patterns exactly (Bandura, 2001).

From another broad perspective, human being learns to behave in each culture through observing other men and women in that culture (Bandura, 2001). Moreover, they will accept those aspects of culture which are more attractive to them. The same is true about women in Iran. Through observing equality of men and women in developing countries, they have learned and internalized such values and react against traditional values. Because of awareness and feminist activities, women have reached sufficiency to think that they are able to revolutionize.

Implication of the study: Theoretically speaking, the general belief is that aggression is shown by men against women and they particularly considered aggression as a masculine behaviour. However, recent studies indicated that aggression takes place in the context of familial relations so it should be noted that aggression can be shown by both genders. The researchers must have broader insights toward aggression and acknowledge the importance of aggression by both men and women. Concerning aggression in the Iranian society and the Iranian families, it should be noted that aggression has grown its roots in the society and many families, unfortunately both women and men suffered from it.

In the contribution to the current practice, majority of the studies have denied or ignored women's aggression and have focused their sole attention on men's aggression against women. They have analysed the problems that have caused men's aggression against women.

\section{CONCLUSION}

Research on women's aggression and investigation is still in its initial stages in Iran and there is a need in the pursuit of such research. In regards to the spread of aggression among women, especially of the psychological type, the destructive effect of psychological aggression must be given greater emphasis as compared to physical aggression. This matter should be discussed in academic and university level and should carry out further research on this issue.

The family disputes, like any other social problems and issues, are bilateral. Both men and women played a role in creating them. The real reason for these quarrels will be understood only through studying aggression on both genders. This taboo of studying women's aggression should be based on the existing literature. Everybody must be aware that there is no difference between men and women in showing aggressive behaviour but that there is equal likelihood for the amount and type of aggression in both genders. Consequently, women's aggression should receive equal attention to men's. In both cases should be studied in the context and conditions in which aggression occurs. Only in these situations will there be better results, as well as healthier and better families.

Recommendations for future studies: The present study used Straus questionnaire (CTS) to determine the type of women's physical and psychological aggression. It has measured the physical and psychological aggressiveness. The women suffering from sexual or economical aggressiveness are not identified in this questionnaire. For better identification of the types of aggressiveness in women, a modified version of the questionnaire must be recommended. As a result, it failed to study all different types of women's aggression and other types of aggression such as sexual or economical aggression that resulted to incomplete understanding of other types of aggression in Iran. 
The next limitation was regarding to the women who were referred to the clinics. This issue is due to the existing traditional attitudes. All women from different ethnic and social groups did not get referred to the clinics and so the sample selected may not be a true representative of the aggressive women population. Moreover, this study did not include divorced women.

\section{REFERENCES}

Bandura, A., 2001. Social cognitive theory: An agentic perspective. Ann. Rev. Psychol. 52: 1-26. http://www.ncbi.nlm.nih.gov/pubmed/11148297

Caetano, R., J. Schafter, C. Field and S.M. Nelson, 2002. Agreement on reports of intimate partner violence among white, black and Hispanic couples in the United States. J. Int. Violen., 17: 1308-1322. http://cat.inist.fr/?aModele $=$ afficheN\&cpsidt $=1404$ 1049

Dutton, D.G., 2006. Rethinking Domestic Violence. 1st Edn., UBC Press, Vancouver, ISBN: 10: 0774810157, pp: 432.

Ehzazi, S., 2004. Society structure and violence against women. Soc. Welfare, 4: 47-84. http://www.sid.ir/En/ViewPaper.asp?ID=26569\&v $\operatorname{arStr}=7$;EZAZI\%20SH.;SOCIAL\%20WELFARE; Fall\%202004;4;14;47;84

Harned, M.S., 2001. Abused women or abused men? An examination of the context and outcomes of dating violence. Violen. Vict., 16: 269-285. http://www.ncbi.nlm.nih.gov/pubmed/11437117

Kar, M., 2000a. Violence against Women in Iran. Roshangaran, Theran, 1: 36-59.

Kar, M., 2000b. Women and discrimination. Noghreh, Tehran, 1: 20-45.

Krejcie, R.V. and D.W. Morgan, 1970. Determining sample size for research activities. Educ. Psychol. Measure., 30: 607-610. http://people.usd.edu/ mbaron/edad810/Krejcie.pd $\mathrm{f}$
Moazami, S., 2004. Crime and violence in the family. J. Female Res., 2: 39-53.

O'Leary, S.G. and A.M.S. Slep, 2006. Precipitants of partner aggression. J. Fam. Psychol., 20: 344-347. http://www.ncbi.nlm.nih.gov/pubmed/16756412

Simonelli, C.J., T. Mullis, A.N. Elliot and T.W. Pierce, 2002. Abuse by siblings and subsequent experiences of violence within the dating relationship. J. Interperson. Violen., 17: 103-121. http://jiv.sagepub.com/cgi/content/abstract/17/2/10 3

Shook, N.J., D.A. Gerrity, J. Jurich and A.E. Segrist, 2000. Courtship violence among college students: A comparison of verbally and physically abusive couples. J. Fam. Violen., 15: 1-22. DOI: 10.1023/A:1007532718917

Straus, M.A. 1979. Measuring intrafamily conflict and violence: The Conflict Tactics (CT) scale. J. Marriage $\quad$ Fam., 41: 75-88. http://www.jstor.org/pss/351733 